\title{
CINE DE AUTOR CONTEMPORANEO: Cruces con el horror
}

Sería un asunto complicado encasillar sus obras en un solo género. Directores como Kubrick, Lynch, Burton, Tarantino o Weerasethakul no son directores emblemáticos del cinedeterror, pero los préstamos que de él toman tiñen de un aire extraño sus películas. Sus trabajos transitan por diferentes territorios y dejan abiertas múltiples ventanas de interpretación. Hemos dedicado un espacio para ellos.

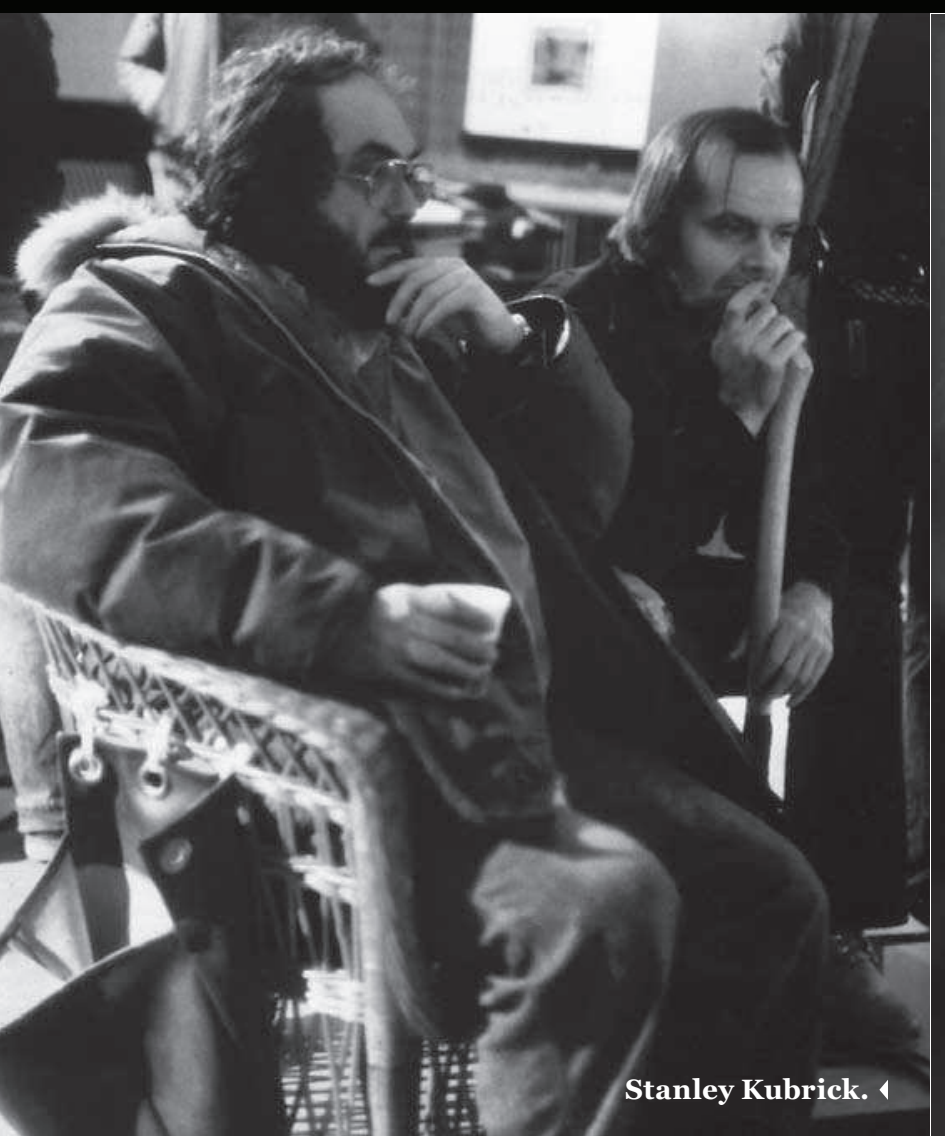




\section{Stanley Kubrick y el horror político}

Aunque en ocasiones el extraño director de Dr. Strangelove (¿Teléfono rojo?, volamos hacia Moscú, 1964) se quiso presentar como todo un satirista, nunca estuvo más cerca de una posible etiqueta que la del especialista del horror. Lo era incluso desde las insidiosas tramas del film noir que marcaron el paso de su inaugurada carrera en el cine a mediados de los años cincuenta, en las que ponía en práctica su sentido excéntrico del espectáculo, de atmósferas enrarecidas, planos desconcertantes introducidos aquí y allá, y por supuesto su uso de la fotografía y sus contrapuntos con la banda sonora. Solo una vez que se convirtió en el creador con cuota de decisión sobre sus películas es que pudo poner sobre la mesa la personal forma en que veía esos infiernos modernos que le generarían un culto aún creciente.

Aunque casi ninguna película suya se encuentre exenta de ello, sus incursiones más próximas a lo que tradicionalmente podemos llamar terror cinematográfico, serían sus adaptaciones de La naranja mecánica de Anthony Burgess y El resplandor de Stephen King, ese autor tan poco comprendido muchas veces y de quien no sería nada descabellado imaginar que Kubrick pudiera haberse considerado muy cercano. Ambicioso como era, el director neoyorquino dejó como ejemplos de su sentido del espectáculo y de su ideología escenas en las que resume, cual demiurgo, toda esa percepción del mundo muy próxima y a la vez muy diferente de las de ese auténtico moralismo, desencantado, apesadumbrado, empleando lo irrisorio como forma de consuelo.
En La naranja mecánica (A clockwork orange, 1971), el tránsito episódico y circular de Álex lo lleva de la escalada violentista del gamberro a la del promisorio outsider político, que se concentra a la perfección en aquel momento en el que recibe la prolongada tortura programada con la Novena de Beethoven. La melodía se distorsiona en el momento en el que dejamos al antihéroe retorciéndose en la habitación mientras la cámara se aleja dejando ver a una siniestra comparsa de intelectuales subversivos dispuestos a tantas ignominias como las del sistema contra el que están conjurados. Es una imagen tortuosa, acaso tan fuerte como las hipnóticas y dilatadas que mostraban el paradójico infinito condensado de 2001: Odisea del espacio, y debe de ser el momento más afortunado en el que Kubrick extendió esa percepción del terror a secas hacia algo todavía más virulento, concreto y perturbador, como el terrorismo de Estado.

De ello no está libre, en una veta aparentemente más comercial, el trávelin más famoso de El resplandor (The shining, 1980), en el que el enloquecido Jack Torrance persigue a su hijo a través del nevado laberinto afuera del enorme y aislado hotel en el que se enmarca la acción. Como en la novela misma, la metafísica y los llamados viajes interiores son aludidos de forma sorprendente en esa secuencia llevada con una elegante steadycam. Ciclo que termina cerrándose sin una sentencia clara o didáctica sobre los motivos del artista consumiéndose a sí mismo en sus pretensiones o influido por una órbita maléfica y ancestral.
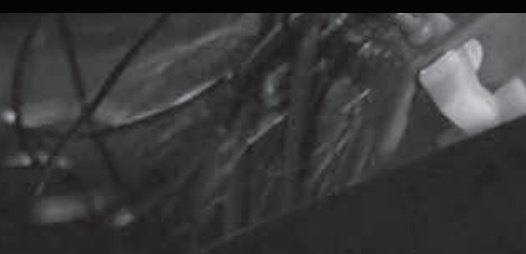

\section{- La naranja mecánica.}




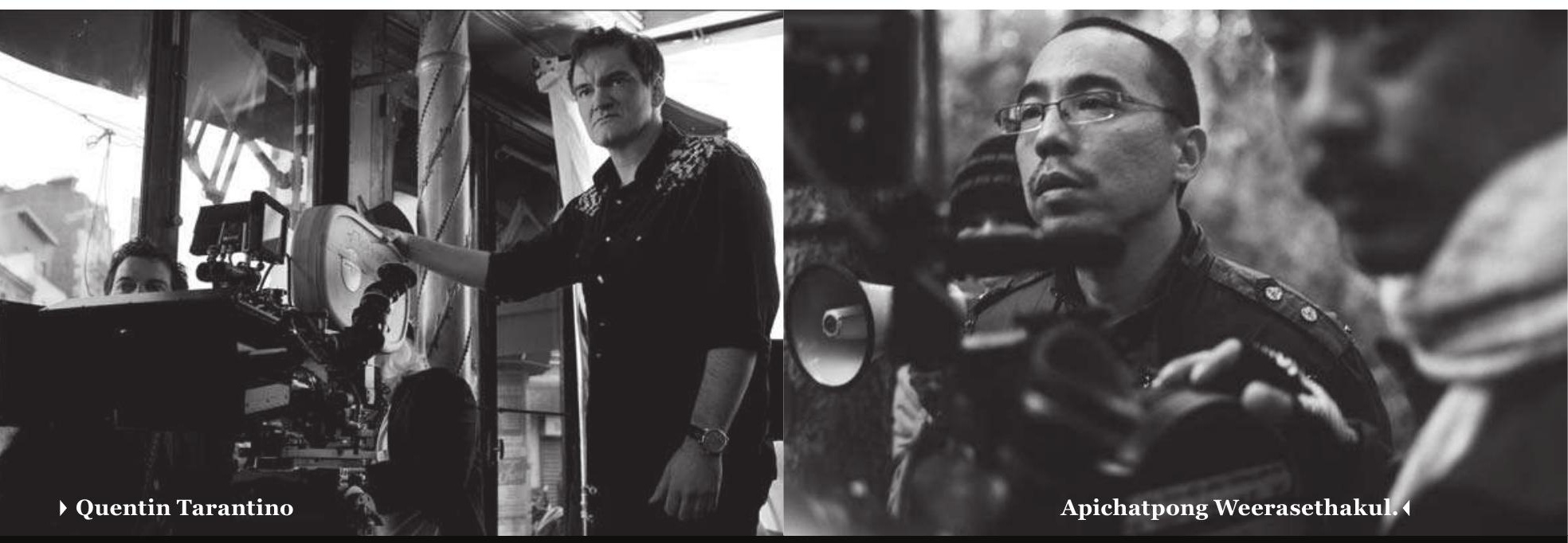

la sombría Ciudad Gótica, el espacio defendido por el hombre murciélago, es amenazada por las armas de colores encendidos que maneja el Joker interpretado por Jack Nicholson; el gótico castillo de El joven manos de tijeras solo tiene cabida para la imaginación fértil y naif del protagonista, mientras que en la localidad adyacente, con sus casas pintadas de colores pastel, se esconden los prejuicios más viles.

José Carlos Cabrejo

\section{Ia oscuridad de Quentin Tarantino}

La utilización de elementos narrativos como personajes orientados hacia el crimen, la maldad y la crueldad, así como de recursos cinematográficos como el alto contraste en el claroscuro, el fuera de campo y la exacerbación de lo explícito mediante los planos detalle, hacen que las películas de Tarantino se aproximen por momentos a una estética representativa del cine de terror. Desde el punto de vista del espectador se actualizarían sensaciones y reacciones relacionadas con el miedo y el horror pudiendo generar incomodidad, intranquilidad, quizá ansiedad y transitando en ocasiones por el asco y la repulsión.

Es importante resaltar a partir de las películas de Tarantino, y en especial en A prueba de muerte (Death proof, 2007), la imperceptible frontera entre las cualidades de los estímulos. El espectro de posibles sensaciones y emociones que pudiera generar deambula simultáneamente entre la aversión y la seducción. La coexistencia de elementos grotescos y atractivos podría provocar una ininterrumpida búsqueda de la certeza en la mente del espectador, aquel cautivado por la exquisitez estética y narrativa de la película, y por la continua cacería tan propia de los slasher films.

Así, en A prueba de muerte, película categóricamente dividida en dos partes, dicha contraposición cualitativa permite hablar de una extrema articulación de elementos fundamentales presentes, como la noche y el día, los malos y los buenos, lo grotesco y lo agradable, lo que precisa y directamente se relaciona con uno de los temas más importantes de la película: los actores principales y los dobles. De manera sincrónica se establece el punto de partida para la existencia de aquel elemento terrorífico que genera inquietud dentro de la ficción, que amenaza a los personajes e intenta cazarlos y que establece las leyes para la estipulación de la aversión y la simpatía desde la mente del espectador.

Bustamante Philipps

\section{Ios fantasmas de Apichatpong Weerasethakul}

Tropical Malady (2004) y El tío Boonmee que recuerda sus vidas pasadas (2010) son dos películas sobre lo espectral. En ellas, el cineasta tailandés muestra personajes en ambientes forestales, que experimentan miedo ante fenómenos sobrenaturales. En la primera, un soldado se encuentra aterrorizado por un chamán convertido en un tigre de mirada fija y penetrante; en la segunda, una familia se inquieta por la presencia de los espíritus de dos seres queridos, uno femenino y de imagen traslúcida, y otro masculino de ojos rojos y resplandecientes, con la piel cubierta de un abundante pelaje negro.

Sin embargo, el miedo se desvanece. El chamán, con su apariencia animal, termina tranquilizando de manera hipnótica al soldado, y la familia acoge con calidez a aquellas dos ánimas. Lo fantasmal en el cine de Weerasethakul se aleja finalmente del horror porque deviene en natural, brota como entidad mítica. Vemos seres fantásticos que emergen del agua, que surcan la vegetación o se refugian en una cueva.

Pero dichas criaturas se convierten en cuerpos palpables, de condición carnal. El soldado de Tropical Malady se enfrenta a un espíritu que también tiene apariencia humana, la de un hombre de cuerpo desnudo y tatuado, con el que se revuelca en la tierra con tensión casi sexual. En El tío Boonmee... una princesa se sumerge en las aguas que corren desde unas cascadas y copula con un pez de plácida voz humana. Las fantasías de Weerasethakul nos atrapan con encuadres casi estáticos, que están dotados de una sensualidad enrarecida, hechizante, bestial.

José Carlos Cabrejo 